\title{
Use of Eelgrass, Zostera marina, Wrack by Three Species of Ladybird Beetles (Coleoptera: Coccinellidae) in Prince Edward Island
}

\author{
David J. Garbary, Sarah Fraser, Carrie Ferguson, and Randolph F. LaufF \\ Department of Biology, St. Francis Xavier University, Antigonish, Nova Scotia B2G 2W5 Canada
}

Garbary, David J., Sarah Fraser, Carrie Ferguson, Randolph F. Lauff. 2004. Use of Eelgrass, Zostera marina, wrack by three species of ladybird beetles (Coleoptera: Coccinellidae) in Prince Edward Island. Canadian Field-Naturalist 118(2): 225-228.

Large numbers of the introduced ladybird beetle, Coccinella septempunctata L., were present at Wood Islands and Green Point, Prince Edward Island, in wrack consisting primarily of Zostera marina L. (Eelgrass). The wrack occurred in a 0.5 to $1.0 \mathrm{~m}$ band parallel to the shore, and was from five to $25 \mathrm{~cm}$ thick. The other ladybirds, Propylea quatuordecimpunctata (L.), an introduced coccinellid also found in high numbers, and an individual of the native Hippodamia tredecimpunctata (Say) were found only at Wood Islands. At both sites the ladybird beetles occurred in the mid-intertidal zone along at least $100 \mathrm{~m}$ of shoreline, and were absent to rare on the terrestrial vegetation above the high tide mark. At four of the other eight sites surveyed, occasional individuals were present in the wrack, but they were no more abundant than could be observed on landward vegetation. Mean densities of C. septempunctata at the two primary sites were $52 \mathrm{~m}^{-2}$ (Green Point) and $410 \mathrm{~m}^{-2}$ (Wood Islands).

Key Words: Coccinella septempunctata, Propylea quatuordecimpunctata, Hippodamia tredecimpunctata, ladybird beetles, Coccinellidae, Zostera marina, Eelgrass, intertidal zone, Prince Edward Island.

With over 150 species and subspecies, the Coccinellidae of Canada and Alaska are a conspicuous and ecologically important element of the terrestrial biota (McNamara 1991). In addition to the native fauna, there is great interest in the distribution of invasive ladybirds and the subsequent loss of native biodiversity (Gordon and Vandenberg 1991). This is also true in eastern Canada where Hoebeke and Wheeler (1996) and McCorquodale (1998) and Majka and McCorquodale (in press) reported the spread of introduced species in the Maritimes.

Despite being a terrestrial family, there are several reports of Coccinellidae from beaches and salt marshes in both freshwater and marine environments (Davis and Gray 1966; Schaefer et al. 1987; Turnock 1996; Pupedis 1997; review by Nalepa et al. 1998). Here we report on the mass occurrence of living ladybird beetles in the marine intertidal of Prince Edward Island and their association with Eelgrass (Zostera marina) wrack.

\section{Materials and Methods}

Ten intertidal locations on Prince Edward Island (Table 1) were visited on 30-31 August 2002 for the examination of Eelgrass wrack as part of a study on Eelgrass decline. An abundant population of ladybird beetles was at site one (Wood Islands), and several hours were spent photographing and quantifying the assemblage. At subsequent sites three individuals inspected the wrack for a minimum of $15 \mathrm{~min}$ along at least $100 \mathrm{~m}$ of shoreline. If only a few beetles were observed, their presence was noted. If many were present, densities were calculated using a $20 \times 20 \mathrm{~cm}$ quadrat. The quad- rat was placed haphazardly on the eelgrass wrack $(n=$ 25) at irregular intervals on the shore.

Characteristics of the primary study sites were: The Wood Islands site was a sandy beach with sandstone outcrops. The primary species of seaweeds associated with the wrack were recorded. Green Point was a salt marsh adjacent to an abandoned wharf, and common plants in the marsh were recorded. At Green Point the wrack was almost exclusively Eelgrass. Characteristics of other sites are mentioned, where necessary, in the body of the text. The weather on both days was mostly bright and sunny; however, a mild rain fell at Marchwater (1800 h, 30 August) and Belmont Provincial Park was extremely windy (0800 h, 31 August). Coordinates of primary sites were determined using a global positioning system (Garmin GPS 12, Olanthe, Kansas; Table 1).

Beetles were identified using the keys in Gordon (1985) and by comparison with specimens in the insect collection at St. Francis Xavier University. Voucher specimens have been deposited in the Herbarium of St. Francis Xavier University (STFX) and in the insect collection.

\section{Results}

Three species of ladybird beetles, Coccinella septempunctata, Hippodamia tredecimpunctata, and Propylea quatuordecimpunctata, were present in intertidal Eelgrass wrack (Zostera marina) in Prince Edward Island during late August. All species were present at Wood Island; however, only C. septempunctata was collected from the other sites. 
TABLE 1. Relative abundance of P. quatuordecimpunctata, H. tredecimpunctata and C. septempunctata in sites across Prince Edward Island, and their corresponding GPS coordinates. "Low" corresponds with an observation of $<5$ individuals.

\begin{tabular}{|c|c|c|}
\hline Site & Coordinates & Abundance \\
\hline \multirow[t]{2}{*}{ Wood Islands } & $45^{\circ} 56^{\prime} \mathrm{N}$ & \\
\hline & $62^{\circ} 45^{\prime} \mathrm{W}$ & Very high \\
\hline \multirow[t]{2}{*}{ St. Peters Bay } & $46^{\circ} 26^{\prime} \mathrm{N}$ & \\
\hline & $62^{\circ} 28^{\prime} \mathrm{W}$ & Absent \\
\hline \multirow[t]{2}{*}{ March Water } & $46^{\circ} 29^{\prime} \mathrm{N}$ & \\
\hline & $63^{\circ} 44^{\prime} \mathrm{W}$ & Absent \\
\hline \multirow[t]{2}{*}{ Belmont Provincial Park } & $46^{\circ} 31^{\prime} \mathrm{N}$ & \\
\hline & $63^{\circ} 49^{\prime} \mathrm{W}$ & Absent \\
\hline \multirow[t]{2}{*}{ Green Point } & $46^{\circ} 35^{\prime} \mathrm{N}$ & \\
\hline & $63^{\circ} 52^{\prime} \mathrm{W}$ & High \\
\hline \multirow[t]{2}{*}{ Cascumpec Bay } & $46^{\circ} 45^{\prime} \mathrm{N}$ & \\
\hline & $64^{\circ} 04^{\prime} \mathrm{W}$ & Absent \\
\hline \multirow[t]{2}{*}{ Linkletter Provincial Park } & $46^{\circ} 24^{\prime} \mathrm{N}$ & \\
\hline & $63^{\circ} 51^{\prime} \mathrm{W}$ & Low \\
\hline \multirow[t]{2}{*}{ Victoria Provincial Park } & $46^{\circ} 12^{\prime} \mathrm{N}$ & \\
\hline & $63^{\circ} 30^{\prime} \mathrm{W}$ & Low \\
\hline \multirow[t]{2}{*}{ West River Bridge } & $46^{\circ} 11^{\prime} \mathrm{N}$ & \\
\hline & $63^{\circ} 14^{\prime} \mathrm{W}$ & Low \\
\hline \multirow[t]{2}{*}{ Pinnette Provincial Park } & $46^{\circ} 04^{\prime} \mathrm{N}$ & \\
\hline & $62^{\circ} 54^{\prime} \mathrm{W}$ & Low \\
\hline
\end{tabular}

At Wood Islands, C. septempunctata occurred primarily in a loose to dense band of Eelgrass wrack, 0.2-1.0 $\mathrm{m}$ wide, that formed in the mid-intertidal zone on a sandy beach (Figure 1). No coccinellid beetles were found in the dry wrack in the splash zone nor in the mixed herbaceous vegetation above the high tide mark. A few beetles were also found in small clumps of wrack lower in the intertidal zone that had recently been inundated by the incoming tide and very gentle wave action. The wrack consisted mostly of leaves of Eelgrass and was mixed with several common seaweeds including the brown algae, Fucus serratus, Chorda filum, Chordaria flagelliformis, and the red algae, Chondrus crispus (Irish moss), Palmaria palmata (Dulse) and Furcellaria lumbricalis. The Eelgrass was relatively fresh and had numerous green leaves.

The beetles were present on the exposed wrack to about two $\mathrm{cm}$ into the wrack mass in loosely packed leaves (Figure 2). Beetle density was $410 \pm 340 \mathrm{~m}^{-2}$ (mean $\pm \mathrm{SD})$. Beetles were absent deep within the 20-30 cm thick wrack bundles. The beetles walked along the surface of the leaves and were single or in clumps of two-five individuals. Occasional beetles were present on the bare sand adjacent to the wrack or on clumps of seaweed (mostly Chorda filum and Fucus serratus) that separated from the main body of wrack. No flying beetles were observed; however, walking beetles occasionally spread their elytra.

At Green Point, the Eelgrass wrack accumulated in a $0.5-2 \mathrm{~m}$ band in the mid-intertidal zone of a salt marsh. This was a typical marsh dominated by Spartina alterniflora in the lower marsh and a mixture of
S. patens, Scirpus americanus, S. maritimus, Glaux maritimus, Triglochin maritima and Limonium nashii in the mid-intertidal zone. At various sites along the shore there was extensive accumulation of old Eelgrass in the upper intertidal zone. The Eelgrass wrack tended to form a blanket that matted down the surrounding vegetation or occasionally was suspended up to $30 \mathrm{~cm}$ above the ground.

The beetles (all C. septempunctata) were found on the Eelgrass in the mid-intertidal zone, with rare individuals on the surrounding grasses and sedges. The insects were common $\left(52 \pm 8.5 \mathrm{~m}^{-2}\right)$ over more than $100 \mathrm{~m}$ of shoreline, and were typically single. Beetles were absent on the upper intertidal wrack, and none were observed in the lower intertidal zone. The insects walked on the Eelgrass and did not fly. In addition to the ladybird beetles, one Leptinotarsa decemlineata (Colorado Potato Beetle) was observed on the wrack.

At Linkletter and Pinnette Provincial Parks and West River Bridge, 3-5 beetles (all C. septempunctata) were found on Eelgrass in the upper intertidal zone. These sites were primarily sand beaches with either scattered clumps or continuous carpets of Eelgrass up to $2 \mathrm{~m}$ wide in the high intertidal zone. At St. Peters Bay, Belmont and Victoria Provincial Parks and Casumpec Bay, beetles were absent, despite the presence of extensive Eelgrass wrack.

Upon our return to Wood Islands, $28 \mathrm{~h}$ after the initial observations, we found that the previous day's wrack had largely disappeared. A few hundred dead ladybird beetles were present in the remaining wrack and on sandstone outcrops along with a few live individuals. 


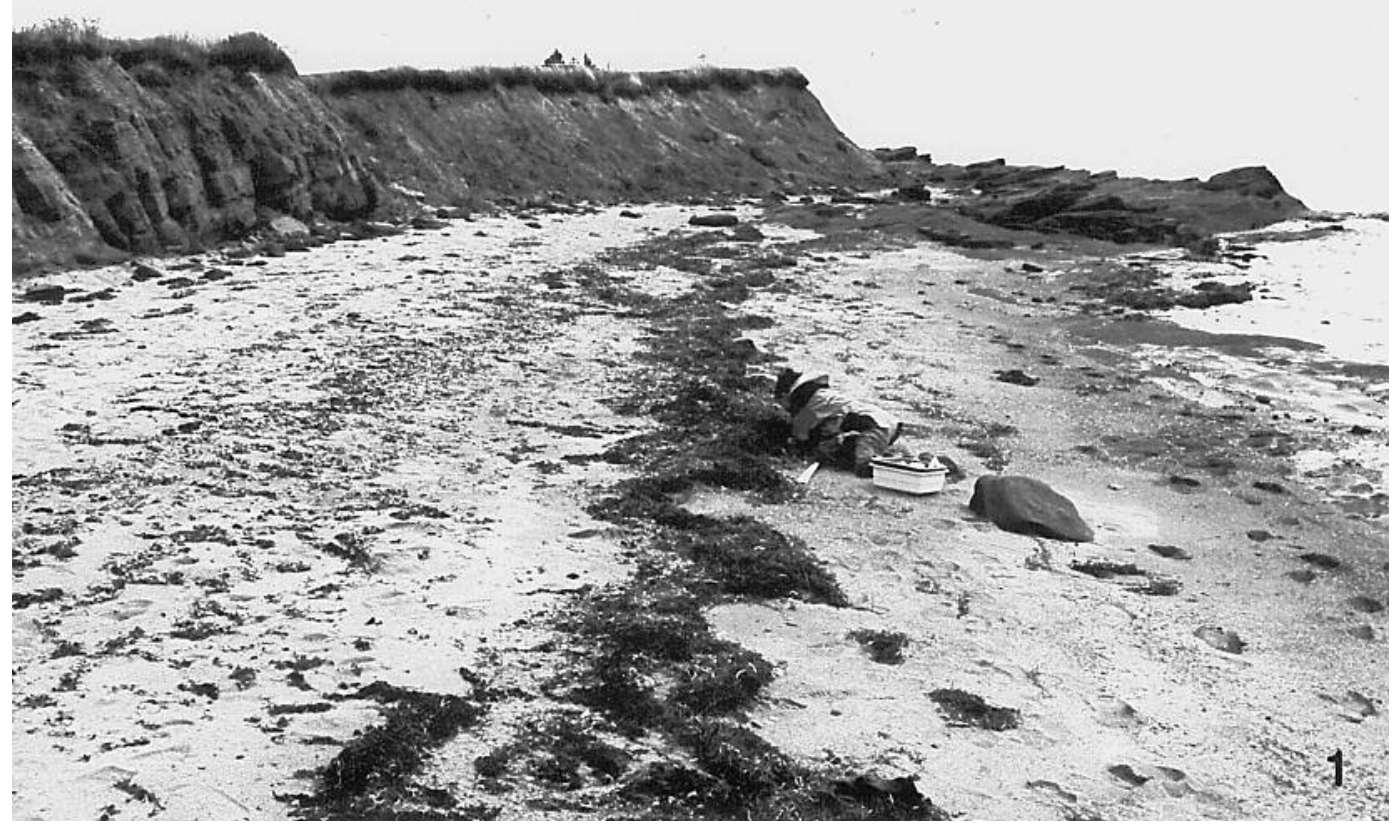

FIGURE 1. Ladybird beetle site at Wood Islands, Prince Edward Island, showing band of intertidal wrack on beach with investigator (C.F.) examining Eelgrass.

\section{Discussion}

Although the records for both introduced species (C. septempunctata, P. quatuordecimpunctata) do not represent range extensions, it is disturbing that they did make up essentially all of the coccinellid fauna at the sampled sites. $P$. quatuordecimpunctata has been recorded in PEI since at least 1994 (Hoebeke and Wheeler 1996). The first records for C. septempunctata on PEI (Charlottetown) are from 1982; it is now abundant in the province (Majka and McCorquodale; in press). The two sites where $C$. septempunctata was abundant shared the feature of having abundant Eelgrass wrack in the mid-intertidal zone. The beetles were generally not found in the older, dry wrack at the upper part of the shore nor in the vegetation above the high tide mark (Wood Islands and Green Point), and the surrounding salt marsh vegetation (Green Point). Examination of the Eelgrass substratum showed no conspicuous populations of invertebrates that might be a suitable food source. In addition, the beetles were sluggish, suggesting exhaustion due to struggling or partial suffocation. The location of the beetles and their behaviour suggest that the they were only recently washed up to the eelgrass wrack, a substrate which allowed them firm footing. Sites with few or no beetles had less fresh Eelgrass wrack. The intertidal substratum at these sites tended to be rockier, with better developed populations of seaweed.

Although terrestrial, both C. septempunctata and Propylea quatuordecimpunctata have previously been found in coastal habitats including salt marshes in
Connecticut, North Carolina and Delaware (Schaefer et al. 1987; Pupedis 1997; Nalepa et al. 1998). Davis and Gray (1966) also reported another ladybird beetle, Naemia serriata, from a salt marsh in North Carolina. The mass occurrences of C. septempunctata that we found are different from that in Delaware in which numerous dead and some living individuals were washed ashore following deposition in the ocean and association with seaweed wrack (Schaefer et al.

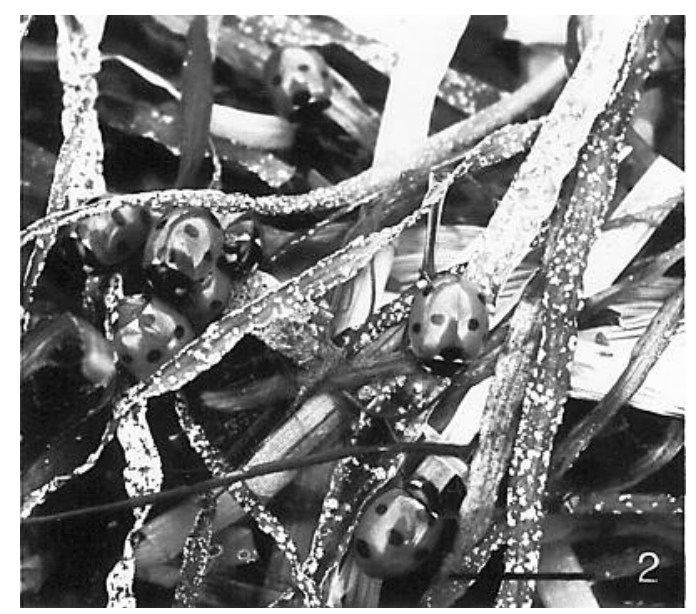

FIGURE 2. Coccinella septempunctata on mid-intertidal Eelgrass wrack. Note: The white spots on the leaves are a calcified red alga. 
1987). The North Carolina mass occurrence is similar to that reported by Schaefer et al., and involved mass mortality and shore deposition (Nalepa et al. 1998). Turnock (1996) suggested that accumulations of lady beetles on the shores of Lake Manitoba resulted from wave deposition and subsequent migration up the shore to structures protruding from the sand. Given the localization of C. septempunctata in this study, particularly at Green Point, the Eelgrass seems to have been a fortunate substratum on which the beetles could take hold, and rest prior to dispersal.

Although there were conspicuous corpses of ladybugs in the wrack at Wood Islands on the day after the survey, the vast majority of the population had disappeared from the shore. There was no evidence that the beetles had moved onto the grassy field adjacent to the beach. Invasions of Coccinellidae into North America show that these species can cover a large distance (Schaefer et al. 1987). McCorquodale (1998) gives range expansion rates of 31-440 $\mathrm{km} \mathrm{y}^{-1}$ across North America for four introduced coccinellids in Nova Scotia, although he concedes that not all of this is likely to be long distance flights. Schaefer et al. (1987) comment on the occurrence of C. septempunctata on Sable Island, $300 \mathrm{~km}$ from mainland Nova Scotia. Thus the $20 \mathrm{~km}$ flight across the Northumberland Strait to or from Nova Scotia is reasonable, especially if a suitable wind is available.

Our records of C. septempunctata on the north and south shores of PEI are consistent with eelgrass providing a staging substratum during migration. Migrations of Hippodamia convergens cover hundreds of kilometres in single flights in California from San Francisco and the Imperial Valley to the Sierra Nevadas (Hodek 1973). However, the aggregations we observed in Prince Edward Island are more likely reflective of accidental downing of migrating populations as a result of weather conditions, followed by subsequent washup. The Eelgrass provided a better refugium than other substrata in the mid-intertidal zone. We suggest that the beetles are only saved by the Eelgrass wrack, and that there is no particular attraction to it as previously described for similar vegetation with $C$. septempunctata (Schaller and Nentwig 2000; Frantsevich and Zolotov 2001).

\section{Acknowledgments}

We thank Christine Nalepa and Chris Majka who provided helpful discussion and literature; the comments of two anonymous reviewers were also an asset to this paper. Barry Taylor kindly assisted with plant identification and David McCorquodale verified identifications of beetles in our insect collection. This work was supported by a grant from the Natural Sciences and Engineering Research Council (NSERC) to D. J. G., funding from the Nova Scotia Museum to R. F. L., and by NSERC undergraduate awards to S. F. and C. F.

\section{Literature Cited}

Davis, L. V., and I. E. Gray. 1966. Zonal and seasonal distribution of insects in North Carolina salt marshes. Ecological Monographs 36: 275-295.

Frantsevich, L. I., and V. V. Zolotov. 2001. Response to contrast of the seven spot ladybird Coccinella septempunctata (Coleoptera, Coccinellidae). Journal of Evolutionary Biochemistry and Physiology 37: 398-404.

Gordon, R. D. 1985. The Coccinellidae (Coleoptera) of America north of Mexico. Journal of the New York Entomological Society 93: 1-912.

Gordon, R. D., and N. Vandenberg. 1991. Field guide to recently introduced species of Coccinellidae (Coleoptera) in North America, with a revised key to North American genera of Coccinellini. Proceedings of the Entomological Society of Washington 93: 845-864.

Hodek, I. 1973. Biology of Coccinellidae. Academia, Prague. 260 pages.

Hoebeke, E. R., and A. G. Wheeler. 1996. Adventive lady beetles (Coleoptera: Coccinellidae) in the Canadian Maritime Provinces, with new eastern U.S. records of Harmonia quadripunctata. Entomological News 107: 281-290.

McCorquodale, D. B. 1998. Adventive lady beetles (Coleoptera: Coccinellidae) in eastern Nova Scotia. Entomological News 109: 15-20.

McNamara, J. 1991. Family Coccinellidae, ladybird beetles. Pages 229-237 in Checklist of beetles of Canada and Alaska. Edited by Y. Bousquet. Publication 1884/E. Agriculture Canada, Ottawa, Ontario.

Nalepa, C. A., K. R. Ahlstrom, B. A. Nault, and J. L. Williams. 1998. Mass appearance of lady beetles (Coleoptera: Coccinellidae) on North Carolina beaches. Entomological News 109: 277-281.

Pupedis, R. J. 1997. Aquatic insects of the West River and salt marshes of Connecticut. Bulletin Series, Yale School of Forestry and Environmental Studies 100: 162-177.

Schaefer, P. W., R. J. Dysart, and H. B. Specht. 1987. North American distribution of Coccinella septempunctata (Coleoptera: Coccinellidae) and its mass appearance in coastal Delaware. Environmental Entomology 16: 368-373.

Schaller, M., and W. Nentwig. 2000. Olfactory orientation of the seven-spot ladybird beetle, Coccinella septempunctata (Coleoptera: Coccinellidae): attraction of adults to plants and conspecific females. European Journal of Entomology 97: 155-159.

Turnock, B. 1996. Lady beetles on the Lake Manitoba beach. University Field Station (Delta Marsh) Annual Report 31: 40-42.

Received 17 September 2002

Accepted 15 November 2004 